\title{
Política e entretenimento: cruzamento e/ou interferência na construção de sentidos
}

\section{Luciana Panke*}

Resumo: O fazer política passa pelo processo eleitoral e, no Brasil, consequentemente, pela produção televisiva. A chamada política das aparências investe em recursos estéticos e adota linguagens específicas de outros ramos da comunicação, como o entretenimento. Nesse sentido, buscamos discutir como se materializam estas linguagens na televisão e, para exemplificar, trazemos um estudo de caso sobre a campanha eleitoral da candidata ao governo de Santa Catarina, pelo Partido dos Trabalhadores, Ideli Salvatti, que adotou a paródia como um recurso para entreter e polemizar.

Palavras-chave: comunicação política; propaganda eleitoral; televisão; Horário Gratuito de Propaganda Eleitoral (HGPE); eleições 2010.

Resumen: El hecho de hacer política pasa por el proceso electoral y, en Brasil, por la producción televisiva. La llamada "política de las apariencias" invierte en recursos estéticos y adopta lenguajes específicos de otras ramas de la comunicación, como el entretenimiento. En ese sentido, se discute cómo se materializan estos lenguajes en la televisión y, para ejemplificar, se plantea un estudio de caso sobre la campaña electoral de la entonces candidata al gobierno de Santa Catarina, por el Partido dos Trabalhadores, Ideli Salvatti, que adoptó la parodia como recurso para entretener y polemizar.

Palabras-clave: comunicación política; propaganda electoral; televisión; Horario Gratuito de Propaganda Electoral (HGPE); elecciones 2010.

Abstract: Politics is intrinsically related to the electoral process and, in Brazil, it is also related to television production. The so-called "politics of appearances" utilizes aesthetic resources and employs specific discourse coming from other areas of communication, such as the area of entertainment. In this sense, we aimed at discussing how this discourse takes form on television and, as an example, we looked into a case study about the electoral campaign of the then candidate for 
State Governor of Santa Catarina, Ideli Salvatti, of the Workers Party, who employed parody as a resource to entertain and create controversy.

Keywords: political communication; political advertisement; television, Free Political Ads; 2010 elections.

A televisão é um dos veículos de comunicação que alia diversos códigos de linguagem, classificando-se, desta forma, como multidimensional (simula a dimensão espacial do mundo real) e multisensorial (devido à variedade de linguagens simultâneas, estimula vários sentidos ao mesmo tempo). Eco (1993) sugere a presença de três códigos principais: código icônico que se refere à imagem em si, composição, estética, edição, angulação; código lingüístico: a presença do texto; e código sonoro composto por ruídos e sons para criar ambientação e músicas para imprimir emoção. Esses códigos interagem com as referências da audiência, e, de acordo com as funções da mensagem, fazem emergir diversos níveis de significado (ECO, 1993, p. 382).

Portanto, tomando ainda o autor como referência, consideramos as seis funções da mensagem: função referencial: direcionar a atenção do espectador para um só referente; função emotiva: provocar emoções, em especial com a associações de ideias, função conativa ou imperativa: levar a uma ação; função fática: estabelecer um contato psicológico com o receptor; função metalingüística: fala de outra mensagem ou de si mesma e função estética: ênfase na harmonia de todas as outras funções. (ECO, 1993, p. 382)

Assim, se aplicarmos estas considerações de Eco, encontraremos nos programas de televisão veiculados no Horário Gratuito de Propaganda Eleitoral (HGPE), uma alternância entre as várias funções com predomínio das funções emotiva, imperativa e fática. Sigamos o raciocínio: para levar um eleitor à ação (função imperativa), o candidato estabelece contato que simula proximidade com seu público (função fática) e conta com o auxílio de recursos de sensibilização para que isso ocorra (função emotiva).

El mensaje visual se construye por la interacción de distintos datos, signos, instrumentos y experiencias que, aunque diversos y complejos, conforman um todo orgánico. Particularmente, desde la postura del emisor, debe tomarse em cuenta las características heterogêneas de la imagen e potenciarlas y direccionarlas.(APRILE, 2008, p. 64) 
Aqui encontramos o domínio da técnica, no qual a política das aparências ganha ênfase nos processos eletivos. Portanto, como afirmou Aprile, a heterogeneidade da imagem é intrínseca à experiência imagética e os diversos dados se moldam para criar ou potencializar sentidos. Com isso, a espetacularização da política, em especial a respeito da forma de propagação das ideias pode gerar o apagamento discursivo de questões centrais. "O espetáculo é a ideologia por excelência, porque expõe e manifesta na sua plenitude a essência de qualquer sistema ideológico: o empobrecimento, a submissão e a negação da vida real" (DEBORD, 1997, p.161-162). A dissociação entre forma e conteúdo, muitas vezes encontrada na propaganda eleitoral, coloca em discussão sobre como fazer ser ouvido em um momento histórico-social de descrédito da classe política. Para Rancière (2010):

A estética e a política são maneiras de organizar o sensível: de dar a entender, de dar a ver, de construir a visibilidade e a inteligibilidade dos acontecimentos. Para mim, é um dado permanente. É diferente da ideia benjaminiana de que o exercício do poder teria se estetizado num momento específico. Benjamin é sensível às formas e manifestações do Terceiro Reich, mas é preciso dizer que o poder sempre funcionou com manifestações espetaculares, seja na Grécia clássica, seja nas monarquias modernas. (RANCIÈRE, 2010)

Portanto, podemos inferir que não necessariamente é pejorativo o amparo de uma estética bem elaborada na atuação política, levando em consideração, inclusive, os aspectos históricos. Uma estética atraente poderia ser uma forma de atrair quem não tem interesse nas questões políticas. Poderíamos afirmar que a harmonia entre os elementos constituintes da mensagem televisiva (som, imagem em movimento, angulação, enfoque, cenário, texto, música) é uma alternativa para que a política seja adaptada para a velocidade e fugacidade do veículo. Cada mídia possui características que propiciam uma forma de abordagem do conteúdo político. A mídia impressa, por exemplo, apresenta, potencialmente, espaço para aprofundar debates, a televisão enquanto veículo massivo apresenta conteúdos superficialmente.

A televisão, conforme falamos anteriormente, possui opções para veiculação de mensagens o que pode, tanto favorecer o entendi- 
mento, quanto gerar torporização. Pode facilitar por conciliar imagem em movimento, sons diversos, texto falado e escrito compondo mensagens que poderiam se aliar a uma "pedagogia" política. Nesse sentido, informações mais propositivas poderiam ser explicadas com o apoio de códigos diversos.

Por outro lado, o torpor é oriundo da utilização do veículo para conduzir a produção das mensagens conforme a angulação mais interessante para o grupo que emite, anulando outros sentidos. As mensagens, em geral, são mais curtas e já estão diluídas em vários códigos que facilitam a decodificação, diminuindo, portanto, a necessidade de "se pensar a respeito”. Gomes (2004) alerta para o risco da lógica do entretenimento tomar conta da discussão política e transformar a propaganda política em "telepropaganda".

O aspecto formal - estético e retórico - das mensagens passa a ser o mais importante, porque está mais adequado à lógica da comunicação, do que os aspectos materiais, de conteúdo, onde, justamente, uma propaganda e um grupo de interesses, um partido e um candidato se distinguem um dos outros. (GOMES, 2004, p. 205-206)

Além disso, enquanto um local presente no cotidiano das pessoas, é inegável a força da televisão enquanto fonte de informação. "Além de sua importância na comunicação indireta, a televisão assume, em muitos casos, o papel de repertório primário de exemplos, fornecendo explicações prontas, incorporadas pelas pessoas à compreensão que têm do mundo político". (ALDÉ, 2004, p. 48) Isto se torna um risco pois a opinião pronta pode vir de fontes que defendem interesses bem definidos, não necessariamente os mesmos de quem assiste à programação. E, nem sempre, os posicionamentos estão evidentes nas mensagens. Como bem lembra Rancière, "a política não é feita de relações de poder, é feita de relações de mundos" (RANCIĖRE, 1996, p. 54). Com isso, as mediações assumem papel preponderante para o encontro entre estas esferas.

Antes de partirmos para a análise de caso, é importante discutir outros aspectos sobre a relação entre televisão e política. Inicialmente, vamos considerar a televisão sob os seguintes aspectos: 
a) Televisão enquanto instituição social e econômica, gerida por grupos de comunicação compostos por interesses dos mais variados;

b) Televisão enquanto mídia que veicula conteúdos de informação e entretenimento para quase a totalidade dos brasileiros. diversas.

c) Televisão enquanto espaço de divulgação de ideologias

Considerando as três possibilidades, temos as formas mais evidentes de intersecção com a política. Primeiro, a participação dos programas jornalísticos na seleção, editoração e veiculação do que cada um considera "fato noticiável". Neste aspecto, conta o que foi notícia e como ela foi contada ou comentada. Ser notícia ou simplesmente não aparecer nos jornais, pode ser considerado um ato política.

Depois, temos a presença, em telenovelas, de temáticas polêmicas ou agendadas na sociedade (muitas vezes pela própria imprensa). A novela "Que rei sou eu”, veiculada na Rede Globo em 1989, ano da primeira eleição direta para presidência da República, é um exemplo clássico desta relação. No quesito "ficção" podemos destacar, ainda, a opinião de apresentadores de programas populares, considerados fortes formadores de opinião.

Terceiro, encontramos a veiculação de propagandas partidárias no decorrer do ano e campanhas governamentais, tanto educativas quanto institucionais. Aqui, os espaços são os mesmos destinados à veiculação comercial tradicional: 30 segundos por inserção, exceto os comunicados e pronunciamentos oficiais que ocorrem de forma esporádica.

Eventualmente, também, as agências de propaganda recorrem ao que se chama de "campanha de oportunidade" e associam produtos a questões políticas discutidas no momento. Um exemplo recente foi o anunciante Bombril, que caricaturou o seu garoto-propaganda como os candidatos ao segundo turno das eleições à Presidência, Dilma Rousseff e José Serra.

Por sua vez, não é muito comum a presença explícita de programas de entretenimento ou apelos comerciais nas campanhas veiculadas no Horário Gratuito de Propaganda Eleitoral. Inclusive, a lei eleitoral proíbe a manifestação comercial nos programas do $\mathrm{HGPE}^{1}$. Vale, ressaltar que em 2010, a campanha do candidato à Presidência da República, Levy Fidelis (PRTB - 57.960 votos) causou estranhamento, pois, ao mesmo tempo, que realizava críticas ao sistema capitalista e à 
gestão pública, exibia marcas de diversos produtos e serviços em seus programas $^{2}$.

\section{Estudo de caso}

Durante uma viagem ao estado de Santa Catarina, em meio à campanha eleitoral de 2010, verificamos que a candidata ao governo estadual pelo Partido dos Trabalhadores, Ideli Salvatti ${ }^{3}$ adotou a paródia como estratégia de veiculação de conteúdos, em diversos programas veiculados na televisão no Horário Gratuito de Propaganda Eleitoral (HGPE). As referidas peças associavam a mensagem política a programas de entretenimento da Rede Globo de Televisão e também a operadora de telecomunicações Embratel. Questionamo-nos, então, se haveria alguma forma de padronização dos programas entre os demais candidatos petistas aos governos estaduais.

Assim, desenvolvemos um estudo exploratório para verificar se outros candidatos do PT usavam a mesma estratégia. Primeiramente, buscamos em todo o Brasil as candidaturas para os governos estaduais. Para a análise, não foram considerados os candidatos de outras legendas apoiados pelo PT, apenas os que se candidataram em nome do Partido. Iniciamos pela região Sul onde o PT possuía dois candidatos próprios: Tarso Genro, no Rio Grande do Sul e Ideli Salvatti ${ }^{4}$, em Santa Catarina; $\mathrm{Na}$ região sudeste, Aloizio Mercadante ${ }^{5}$, em São Paulo. No centro-oeste, Agnelo Santos Queiroz Filho, no Distrito Federal e no Mato Grosso do Sul, José Orcirio Miranda dos Santos, o Zeca do $\mathrm{PT}^{6}$. No nordeste, Jaques Wagner, na Bahia e Marcelo Deda, em Sergipe. Já na Região Norte, no Acre: Sebastião Afonso Viana Macedo - Tião Viana; no Pará: Ana Julia de Vasconcelos Carepa ${ }^{7}$ e em Rondônia: Eduardo Valverde Araújo Alves ${ }^{8}$.

Após observação, por amostragem, de programas veiculados no HGPE por todos estes candidatos, chegamos à conclusão que as campanhas seguiam estratégias de projeção de imagem em comum. Classificamos, de acordo com a estética e conteúdo, em programas: padrão, ataque e exceções. Chamamos de programas padrão, aqueles que estavam alinhados com a estética nacional (qualidade de imagens e investimento na produção sonora) e adotavam um discurso propositivo, valorizando 
conquistas e se ancorando no governo Lula. Os candidatos que aqui se enquadram foram: Tasso Genro ${ }^{9}$ (RS), Agnelo Santos Queiroz Filho ${ }^{10}$ (DF), Jaques Wagner ${ }^{11}$ (BA), Tião Viana ${ }^{12}$ (PA) e Marcelo Deda ${ }^{13}$ (SE). A pesquisa foi realizada durante as eleições, no mês de outubro, e é interessante observar hoje, após os resultados, que todos esses candidatos foram os vencedores. Tema que, no momento não é o foco deste trabalho, mas que merece ser revisto e aprofundado com o devido cruzamento de dados entre as candidaturas vencedoras.

A estratégia de ataque apresentou campanhas voltadas a um discurso crítico, no qual as candidaturas se apoiaram em fazer projeções negativas nos principais adversários. A maioria das campanhas adotou a estética padrão, mas discursivamente investiram no argumento de incompatibilidade. "A incompatibilidade é sempre relativa a circunstâncias contingentes, sejam estas constituídas por leis naturais, fatos particulares ou decisões humanas"(PERELMAN; OLBRECHTS-TYTECA, 1996, p. 223) As exceções se restringem a dois casos: o primeiro se afastou da qualidade estética dos demais candidatos, que foi Eduardo Valverde, em Rondônia; o segundo, Ideli Salvatti, por sua abordagem argumentativa e, a partir de agora, nosso objeto de discussão.

\section{Novelização catarinense}

Entre as campanhas analisadas, a de Ideli Salvatti ${ }^{14}$ (SC) se diferenciou das demais pelo uso de recursos pouco convencionais. Entre eles, paródias de programas populares veiculados pela maior rede de televisão do País, a TV Globo, e também de um comercial veiculado pela empresa de telefonia, Embratel. Facilmente adotada pela comunicação mercadológica, é uma técnica que, na política, é mais encontrada nos jingles, quando sucessos da música popular são transformados em hits eleitorais. A equipe da candidata, entretanto, inovou trazendo para a discussão política um referente relacionado ao entretenimento mais comum do brasileiro médio: a tradicional "novela das 8".

A imagem de abertura de vários programas veiculados no HGPE foi composta por uma arte com o rosto da candidata no fundo, com a expressão "Passione", com a mesma tipologia da atual novela do horário nobre da Rede Globo. "Passione" por Santa Catarina era o início dos programas, apresentando uma comunicação homônima com a novela global, conforme vemos na figura a seguir. 


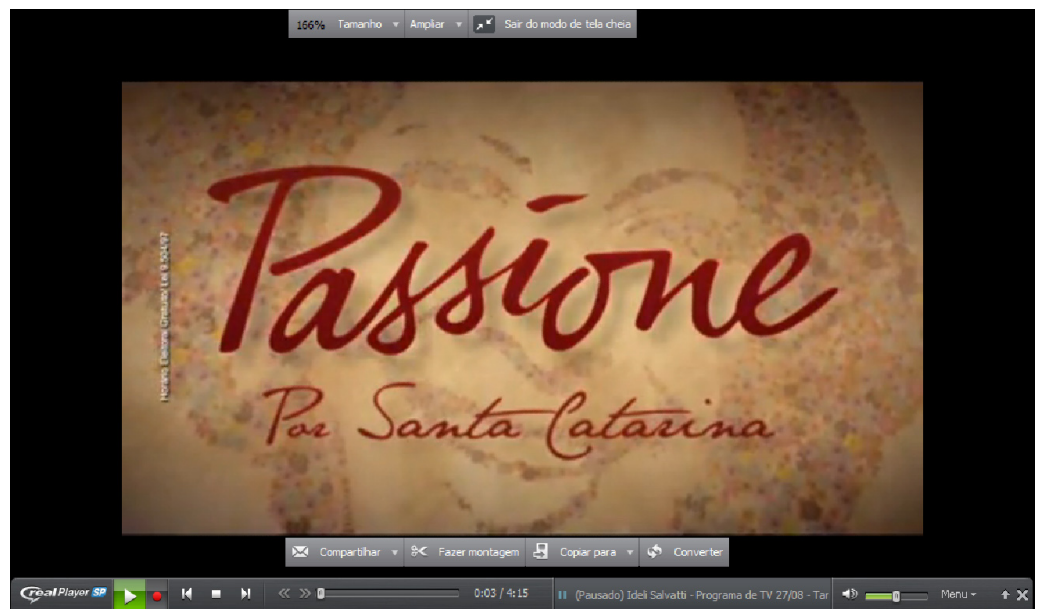

FIGURA 1 - Tela de início de programas da candidata Ideli Salvatti (PT/SC), exibidos no HGPE, em 2010.

Em outro programa, há uma releitura do Programa Mais Vocêㄹ, apresentado por Ana Maria Braga, na Rede Globo de televisão. Na figura a seguir, vemos que a estratégia foi similar à comparação com a novela. Juntamente com as paródias, o discurso irônico também foi adotado como estratégia de ataque a um dos adversários, conforme exemplificamos com o que foi apresentado neste dia.

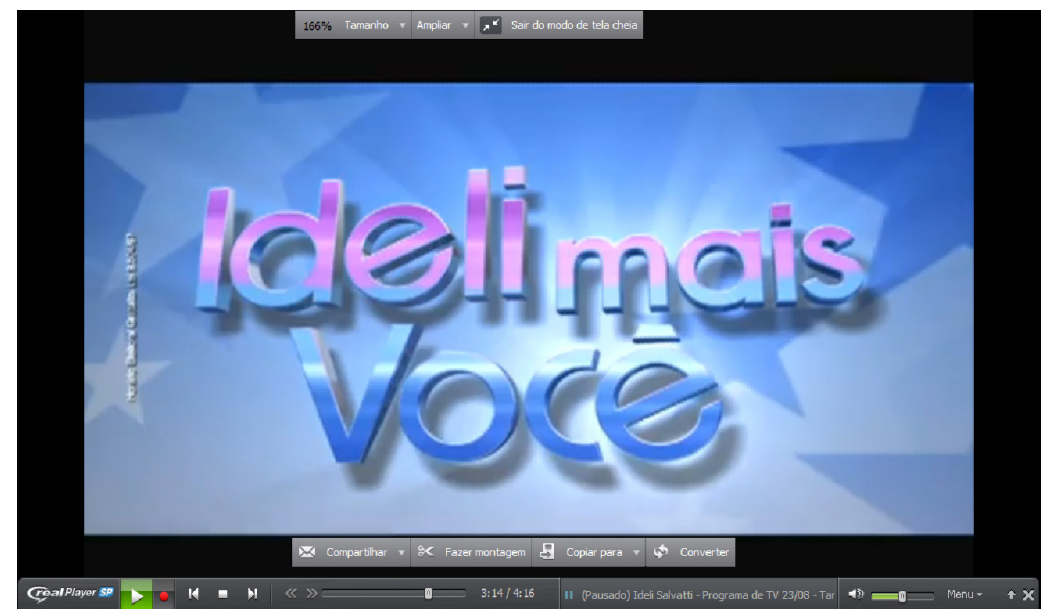

FIGURA 2: Tela de abertura de quadro parodiando o Programa Mais Você, apresentado por Ana Maria Braga e exibido na TV Globo para todo o Brasil no período da manhã. 
Nesse trecho do programa, a candidata encenou um diálogo com o "Louro Zezé". Na cena o papagaio tecia um discurso com promessas genéricas que abrangeriam vários setores. $\mathrm{O}$ personagem falava em tom estereotipado de palanque, apesar do timbre de voz semelhante ao coadjuvante da apresentadora Ana Maria Braga. Na ocasião, o texto $\mathrm{da}$ candidata interrompia o discurso de promessas, questionando: "O que é isso, Louro, você nem se apresentou e já está falando bobiça $a^{16}$ ? Já está falando mentira" (Salvatti, HGPE, 2010) Após o questionamento, e devida "apresentação" do Louro, a candidata também se apresentava. Podemos arriscar a dizer que a opção por "encarnar" a apresentadora Ana Maria Braga (função metalingüística) pode ser uma forma de se aproximar do mesmo público que consome o programa "Mais você" e que admira a apresentadora. Por outro lado, é um risco, porque sempre haverá comparação entre as personagens que se misturam. Neste caso, sem dúvida, a candidata assume um papel de interpretação em uma paródia ficcional que é enquadrada na lógica do entretenimento aplicada à política.

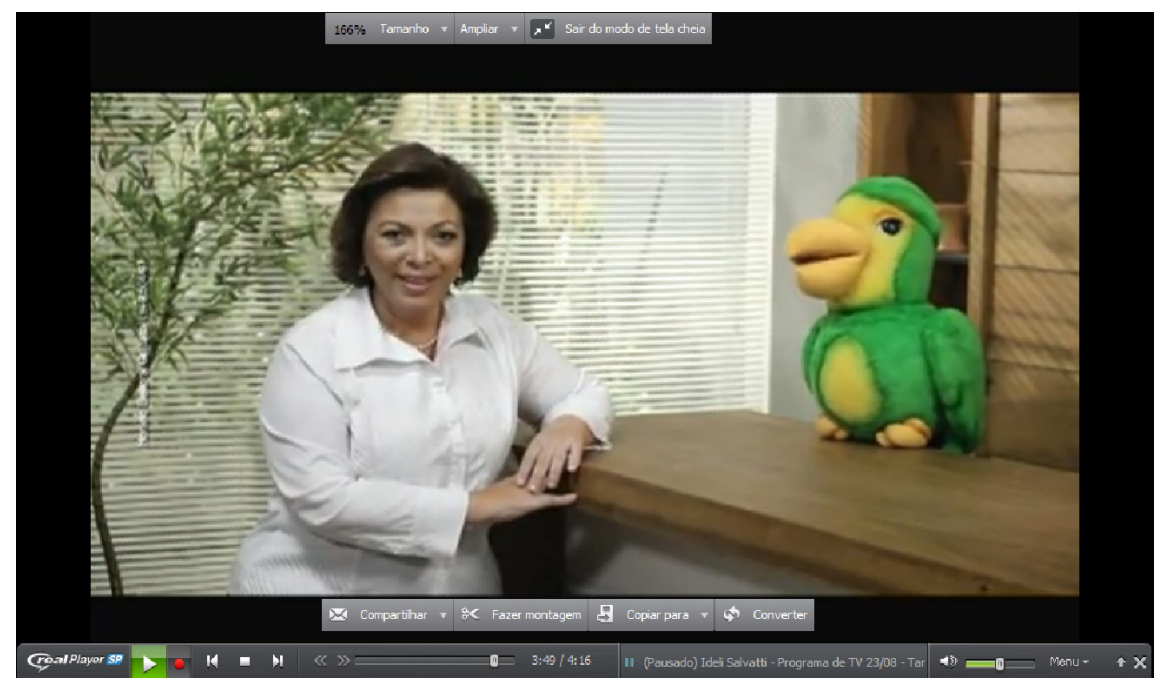

FIGURA 3: Candidata encena com personagem inspirado no programa matinal Mais Você.

Aqui, observamos a própria candidata em situação dramatúrgica ao prover ataque indireto ao oponente Raimundo Colombo ${ }^{17}$ (DEM) através da paródia e do discurso irônico. "A materialização do interessante é o show, o espetáculo, onde tudo é agradável ou extraordinário, 
brilhante ou admirável, leve e veloz, quase virtiginoso" (GOMES, 2004, p. 205. Grifos do autor) A composição do cenário, como podemos ver na figura 3, remete ao programa da apresentadora Global, bem como a presença do fantoche e a postura da então candidata, ao contracenar o episódio.

Tal estratégia de ataque esteve presente no decorrer de toda campanha, variando apenas o grau de explicitação das críticas. Outro formato adotado com freqüência foi a contação de histórias, também com o apoio de elementos lúdicos, para promover comparações, ora para desacreditar o oponente, ora para engrandecer o governo Lula.

O discurso de Ideli seguiu a estratégia nacional de ancoragem $^{18}$ em Lula, trazendo depoimentos do Presidente e da candidata do PT à Presidência, Dilma Rousseff. Produziu, também, um jingle que se apropriou do argumento de transitividade (Perelman e OlbrechtsTyteca, 1996) no qual dois elementos se relacionam simetricamente. "É Lula e Dilma lá e ela aqui. Santa Catarina vai ganhar com Ideli”. O refrão era cantado em vários ritmos e pela sonoridade e rima conseguia promover a memorização.

A campanha como um todo oscilava entre manter a estética nacional e a promoção de ataques ao opositor. Ao mesmo tempo em que o discurso promovia a biografia de Salvatti, apresentava elementos para gerar questionamentos sobre idoneidade de Colombo. As polêmicas eram lançadas, como estamos vendo, dentro da "moldura do show business audiovisual" (GOMES, 2004, p. 205). Não era simplesmente o "ataque pelo ataque", mas peças elaboradas cuidadosamente para gerar ritmo e atração visual durante os programas. Ainda segundo Gomes (2004, p. 2006) "as formas dramáticas e emocionais, construídas segundo as figuras e os tópicos da retórica do entretenimento, tornam-se preferidas em face das fórmulas discursivas, que se chocam frontalmente com a dimensão espetacular da comunicação".

Nesse sentido, a contação de histórias a que nos referimos anteriormente, trazia personagens diversos. Conforme a figura abaixo, vemos a tela introdutória da crítica feita por uma personagem representante de uma idosa. 


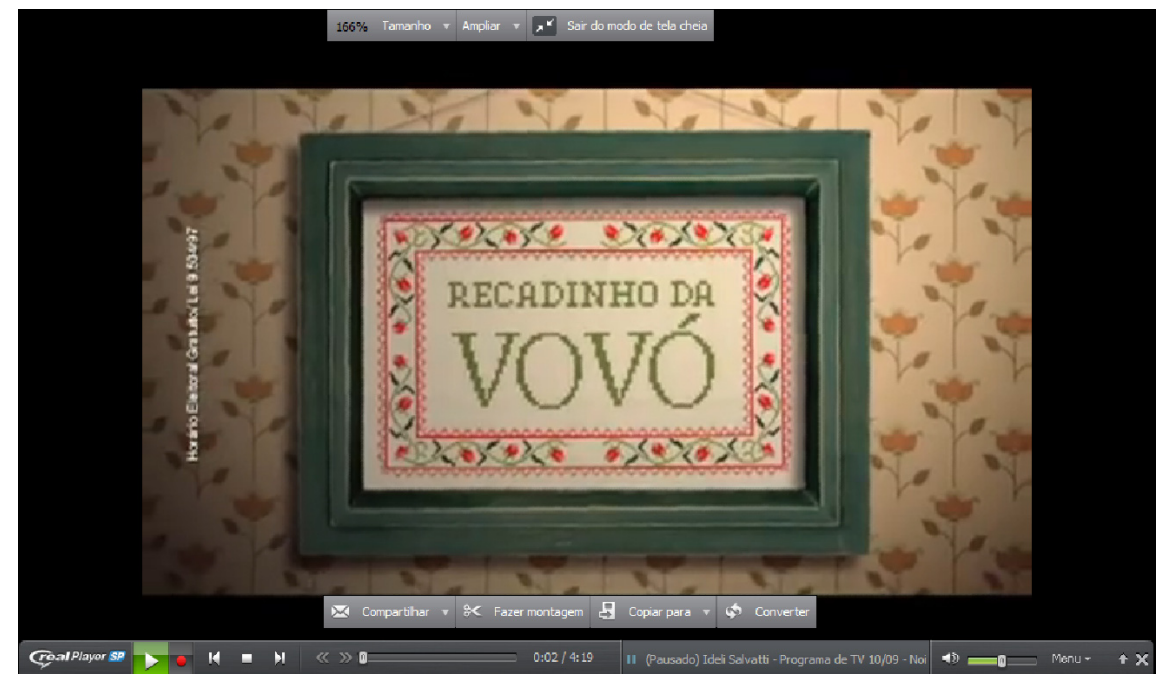

FIGURA 4: Estética com elementos presentes em estereótipos do que seria uma avó: parede forrada e quadro bordado.

A atriz falava olhando para a câmera, em um tom pausado, dirigindo-se a um interlocutor ausente, mas presente no discurso. Eco (1984) argumenta que o enunciador que fala olhando para a câmera produz seu discurso consciente da midiatização da mensagem.

Colocado à frente do expectador, este percebe que aquele se dirige exatamente a ele, através do meio tevê, sugerindolhe, implicitamente, que há algo de 'verdadeiro' na relação que está sendo instituída, independentemente do fato de que ele esteja prestando informações ou contando simplesmente uma história fictícia. (ECO, 1984, p. 188)

Assim, a fala do personagem que o programa da candidata petista apresentava, modulava a voz, alternando com o trabalho manual que realizava. Para reforçar o tom de um suposto diálogo, a cena investiu na produção esteriotipada da figura idônea da avó, que faz tricô, sentada em cadeira de balanço. O texto dizia:

Raimundo, você vive falando que vai melhorar a vida das pessoas, mas como é que você fala isso? Você sempre foi contra o Lula, a Dilma e a Ideli. E, Raimundo, o Lula, a Dilma e a Ideli fizeram muito pelos catarinenses nos últimos anos. $\mathrm{E}$ você esteve no Senado, nos últimos quatro anos, mas eu não 
lembro bem o que você fez por Santa Catarina nesse tempo todo. $\mathrm{O}$ que eu lembro bem, Raimundo, é que você era líder da oposição ao Lula. Eu estou velha, mas não estou gagá, Raimundo. (Programa de Ideli Salvatti, HGPE,10/09/2010 ${ }^{19}$ )

A crítica direta relaciona-se à articulação política em si e questiona como o opositor vai realizar promessas se não teria o apoio necessário para tal. $\mathrm{O}$ argumento de incompatibilidade está presente ao tentar demonstrar as supostas incoerências do outro candidato. "Duas afirmações de uma só pessoa, em momentos diferentes da sua vida, podem ser apresentadas como incompatíveis, se todos os enunciados dessa pessoa são tratados como formando um único sistema" (PERELMAN; OLBRECHTS-TYTECA, 1996, p. 229) Apesar de não apresentar as falas onde supostamente mostrariam que o candidato Colombo não teria a força política necessária para governar o Estado, o texto insinua justamente a presença dessas duas ações.

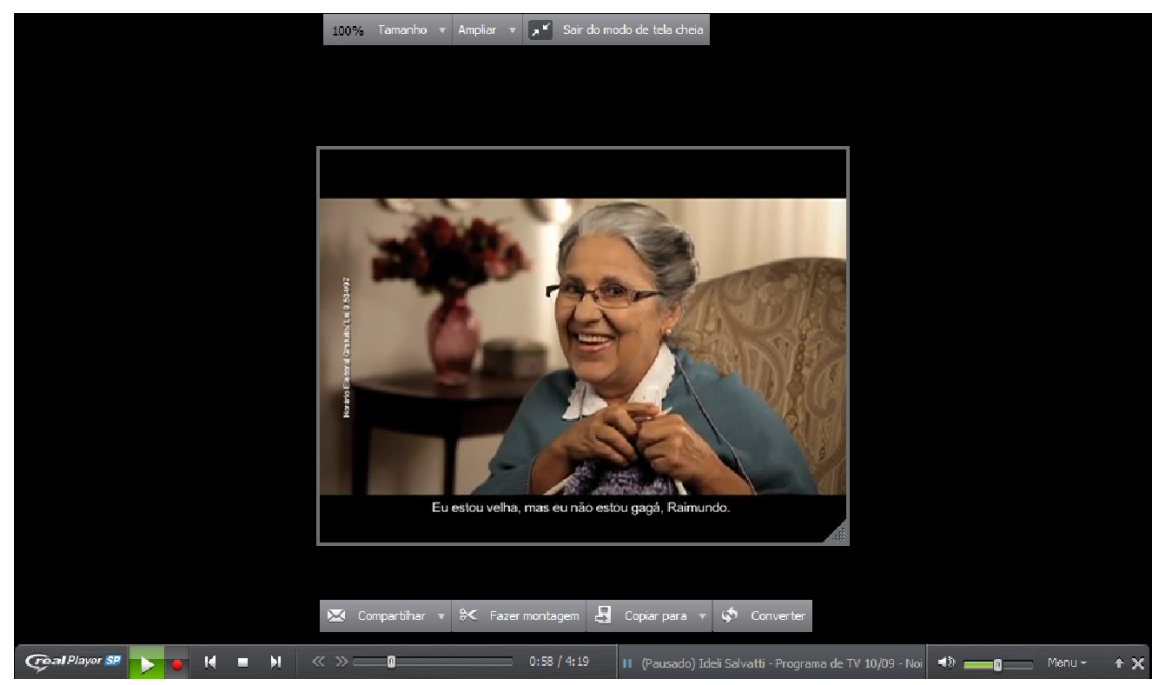

FIGURA 5: Personagem ligado ao estereótipo da avó "idônea” questiona opositor em tom irônico.

No programa anterior, inclusive, o antagonismo ficou mais evidente quando a campanha aproveitou o mote da operadora telefônica Embratel para criar uma peça veiculada em 08/09/2010, parodiando o mote da campanha publicitária: "Tá barato pra caramba! ${ }^{20 "}$ 


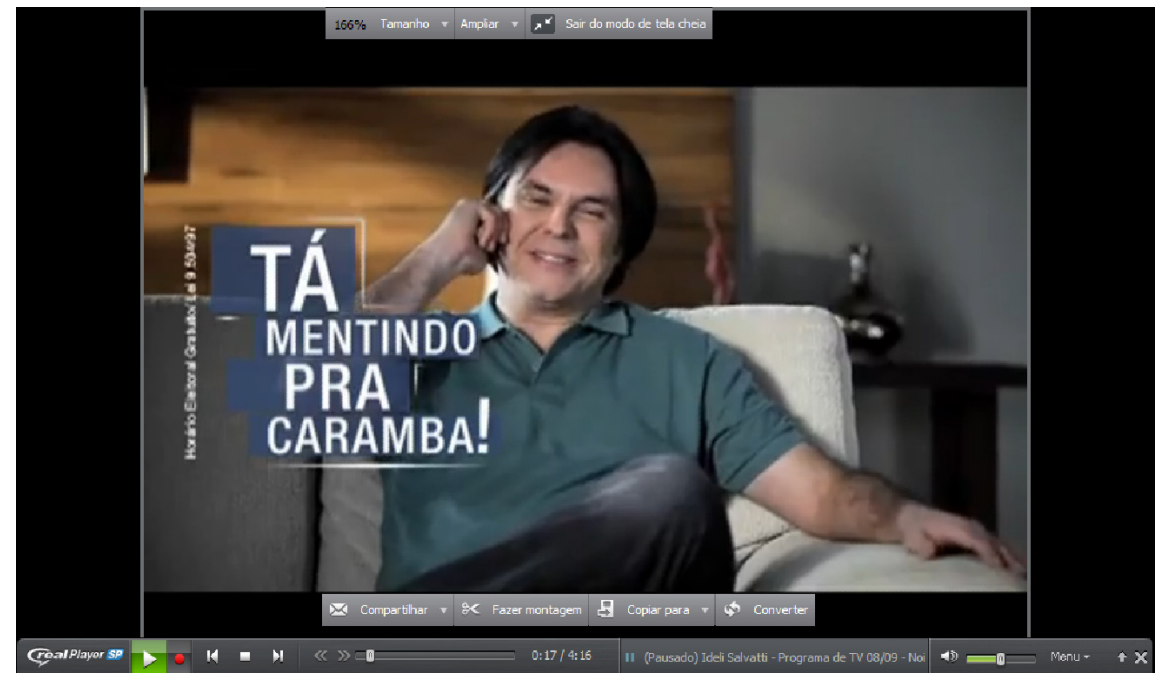

FIGURA 6: Cena de encerramento da paródia do comercial da Embratel.

O texto trazia um diálogo entre dois personagens, que insinuavam que Raimundo Colombo estaria mentindo ao afirmar que construíra hospital na sua cidade de origem, Lages. Ao encenar um comercial veiculado intensamente pelo anunciante original, havia uma reprodução de um discurso já dito mediatizado, gerando a função metalingüística (ECO, 1993). Em segundo plano, podemos constatar uma aproximação com a função emotiva, ao tentar provocar o riso dos receptores. Em outros momentos da campanha, a campanha do DEM esclarecia que era uma ampliação do hospital, mas estes dados não partiram do candidato em si.

(mulher) E aí, você viu aquele candidato dizendo que fez o hospital na cidade dele?

(homem) Eu ouvi, mas como é que pode? Minha mãe nasceu lá em 43.

(mulher) Nossa! Mas ele nem tinha nascido e já estava construindo hospital? Esse candidato é bom mesmo, hein?

(homem) Ou então, tá mentindo pra caramba! (Programa de Ideli Salvatti, HGPE, 08 de setembro de 2010, período da noite.)

Ao resgatar um produto mercadológico veiculado nacionalmente, apresenta-se uma lógica que parece confusa desde o momen- 
to que houve cruzamento de esferas diferenciadas no debate eleitoral. "Uma subjetivação política é uma capacidade de produzir essas cenas polêmicas, essas cenas paradoxais que revelam a contradição de duas lógicas, ao colocar existências que são ao mesmo tempo inexistências ou inexistências que são ao mesmo tempo existências" (RANCIÈRE, 1996, p. 52)

Ao mesclar o enfoque da campanha entre biografia, ancoragem com o Presidente Lula e ataques ao oponente Raimundo Colombo, a campanha de Idelli Salvatti oscilava entre a padronização estética dos programas dos candidatos petistas e a incoerência ideológica, uma vez que optou por adotar aqueles referentes comerciais e "globais" como chamariz para seu público. Dessa forma, pode-se dizer que a candidata criou uma nova categoria para o ataque na propaganda eleitoral: o sarcasmo parodiado.

O que se observou foi o investimento em uma forma inovadora, em detrimento da defesa efetiva de propostas.

Este residuo (os discursos longos, com raciocínios sutis ou sofisticados, ou que exijam grande competência cultural do espectador, por exemplo) é o inevitável aspecto tedioso e frio da telepropaganda, extemporâneo da lógica do entretenimento ou, para usar o termo característico desta época de velocidade e leveza, é o aspecto chato da propaganda política. (GOMES, 2004, p. 206. Grifos do autor)

Ao mesmo tempo em que a maioria dos espaços da televisão não seja, efetivamente, sujeita ao conteúdo mais elaborado, não se pode ignorar as características do veículo. Se a tevê é considerada pelos "apocalípticos” um local de veiculação de mensagens curtas e superficiais para uma massa sujeita à manipulação, há de se convir, por outro lado, que a mesma tevê pode ter como vantagem, justamente, a veiculação de mensagens simplificadas. Fazer política não precisa ser complicado, muito menos ser elitizado. É fato, porém, que os programas veiculados no Horário Gratuito de Propaganda Eleitoral raramente vão deixar de se adaptar à telepropaganda. Por isso, observa-se a necessidade de buscar um equilíbrio entre a predominância da forma em detrimento do conteúdo. Assim, um conteúdo instigante pode ser apresentado sem recorrer ao que Gomes anteriormente denominou, com propriedade, "o aspecto chato da propaganda política”. 


\section{Considerações finais}

A forma atual de estruturação da comunicação eleitoral brasielira, traz diversos questionamentos. Entre eles, a exaustão das fórmulas adotadas na produção de programas veiculados no Horário Gratuito de Propaganda Eleitoral. Enquanto a informação é negligenciada, camuflada e distorcida em favor de uma política das aparências, corre-se o risco de diminuir a audiência dessa fonte, teoricamente, democrática de apresentação de propostas dos candidatos aos cargos eletivos.

As características da comunicação audiovisual tanto favorecem o entendimento das mensagens, quanto propiciam alternativas para desviar a atenção para fatos menos importantes, bem como construir novos significados a cada reconstrução dos mesmos códigos. $\mathrm{O}$ apelo emocional proporcionado pela união de imagem em movimento com músicas, por exemplo, pode ser narcotizante. Outro exemplo, conforme verificamos no estudo de caso, é a reconfiguração de elementos culturais já conhecidos.

Como constatamos, a campanha analisada trouxe ao HGPE paródias de produtos de entretenimento populares, bem como de produtos comerciais. Pelo visto, este recurso que intencionava afastar eleitores do governador eleito em Santa Catarina, fez com que predominasse a função metalingüística $(\mathrm{ECO}, 1993)$ na composição da mensagem. Sensibilizar pelo riso, pela ironia, e, consequentemente, levar à ação, também eram objetivos daquela comunicação.

Talvez a opção por se associar a programas televisivos de grande audiência, mesmo que oriundos da TV Globo, historicamente criticada por segmentos do PT, tenha se originado na tentativa de aproximação com o eleitor, tendo em vista um público médio. Conforme reforça Lima (2002, p.81): "a comunicação eleitoral deve fazer com que essas predisposições (ou tendências políticas), muitas vezes inconscientes por parte do eleitor, sejam estimuladas de forma a se transformarem em uma atitude favorável à candidatura, no menor prazo de tempo e no maior número de indivíduos possível". É possível inferir que o discurso político eleitoral convencional talvez não gerasse comunicação com aquele eleitorado.

Neste sentido, percebemos que a política das aparências, reforçada pelos recursos televisivos, aperfeiçoa a lógica do entreter. Desde 
modo, politizar, ao se encaixar neste esquema, fica condicionado a propagar superficialidades. Conforme o alerta de Debord (1997, p.15): "sob todas as suas formas particulares de informação ou propaganda, publicidade ou consumo direto do entretenimento, o espetáculo constitui o modelo presente da vida socialmente dominante".

Entretanto, consideramos necessária a sensibilização para ação política. Para que isso ocorra, é preciso repensar os modelos de propaganda eleitoral presentes de forma que conteúdo e forma entrem em equilíbrio. Como argumenta Rancière (1996), "a 'estética'é, ao contrário, o que coloca em comunicação, regimes separados de expressão”. (RANCIẼRE, 1996, p. 68). A questão é que conflito de interesses é inerente ao embate político. Para isso, a profusão de ideias é fundamental e, na nossa sociedade, recursos midiáticos são os principais meios para que isto percorra grupos diversos de eleitores.

Sem dúvida, é necessário verificar as formas de condução da comunicação eleitoral para que o discutir política não permaneça sinônimo de "chato" ou de "desnecessário". Entretanto é importante, também, não misturar estratégias de produção de conteúdo a ponto de que aumente ainda mais a ridicularização de vários segmentos do setor.

\section{Referências}

ALDÉ, Alessandra. A construção da política: democracia, cidadania e meios de comunicação de massa. Rio de Janeiro: FGV, 2004.

APRILE, Orlando. La publicidad audiovisual. Del Blanco y negro a La Web. Buenos Aires: La Crujía ediciones, 2008.

DEBORD, Guy. A sociedade do espetáculo. Rio de Janeiro: Contraponto, 1997.

ECO, Umberto. Viagem à irrealidade cotidiana. Rio de Janeiro: Nova Fronteira, 1984.

. Apocalipticos e integrados. São Paulo: Perspectiva, 1993.

GOMES, Wilson. Transformaçôes da politica na era da comunicaşão de massa. São Paulo: Paulus, 2004.

LIMA, Marcelo Coutinho. Marketing eleitoral. Versão para ebook: eBooksBrasil.com, 2002. Disponível em www.ebooksbrasil.org/adobeebook/mktpol.pdf Acesso em: 02 de outubro de 2007. 
LONGMAN, Gabriela, VIANA, Diego. Entrevista Jacques Rancière. Revista Cult, março de 2010. Disponível em http://revistacult.uol.com. br/home/2010/03/entrevista-jacques-ranciere/ Acesso em: 17 de agosto de 2010.

PERELMAN, Chaim; OLBRECHTS-TYTECA, Lucie. O tratado da argumentação - a nova retórica. São Paulo: Martins Fontes, 1996.

RANCIÈRE, Jacques. O desentendimento. Política e filosofia. São Paulo: Editora 34, 1996.

\section{Notas}

[1] Ver artigo 44, inciso segundo: “ $§ 20$ No horário reservado para a propaganda eleitoral, não se permitirá utilização comercial ou propaganda realizada com a intenção, ainda que disfarçada ou subliminar, de promover marca ou produto "Lei disponível em http://www.planalto.gov.br/ccivil_03/Leis/L9504.htm

[2] Programa de Levy Fidelix (PRTB) disponível em: http://www.youtube.com/user/ newsimprensa\#p/search/5/pJlTZr_DvQ

[3] Em dezembro de 2010, a então senadora Ideli Salvatti foi indicada pela presidente eleita, Dilma Rousseff, ao Ministério da Pesca.

[4] Ideli Salvatti ficou em 3.o. lugar na disputa, conquistando 21,9\% dos eleitores.

[5] Mercadante disputou com Geraldo Alckmin (PSDB) e ficou na segunda colocação com $35,23 \%$.

[6] Conquistou 42,5\% do eleitorado.

[7] Somou 44,26\% dos votos e foi derrotada por Simão Jatene (PSDB).

[8] O candidato não chegou a disputar o segundo turno e somou 18,16\% dos votos.

[9] Tasso Genro conquistou 54,35\%

[10] Eleito com $66,1 \%$ dos votos.

[11] Jaques Vagner 63,83\%

[12] Tião Viana 50,51\%

[13] Marcelo Deda 52,08\%

[14] Em 2002, Ideli foi a primeira mulher eleita senadora por Santa Catarina. Apesar de ser paulista, foi morar em Santa Catarina na década de 70. Professora, atuava no movimento sindical. Em 1994, foi eleita deputada estadual e reeleita na eleição seguinte. 
[15] Trecho disponível em http://www.youtube.com/watch?v=7j6jNqrYWF4\&featur $\mathrm{e}=$ related

[16] Expressão oral, ausente do dicionário, que significa bobagem e é usada por catarinenses da região de Itajaí. No programa, este regionalismo está inclusive legendado.

[17] O candidato foi eleito com 52, 72\% dos votos válidos.

[18] Neste exemplo, vemos a ancoragem do Partido e a produção de uma encenação lúdica para promover relações entre a candidata e a força de Lula. http://www.youtube. $\mathrm{com} /$ watch?v=7BXp88dDgKE\&feature=related

[19] Programa disponível em http://www.youtube. com/watch?v=AsGHL1BercI\&feature=mfu_in_order\&list=UL. Acesso em 20 set. 2010.

[20] A coligação do candidato Raimundo Colombo entrou com recurso no Tribunal Regional Eleitoral, pedindo direito de resposta, cujo recurso foi negado. Disponível em http://www.tre-sc.gov.br/sj/acordaos/pdfs/2010/25375_.pdf O vídeo, entretanto, não se encontra mais online. 